\title{
Experiment study investigation compare temperature series circuit and the parallel circuit of thermoelectric and variable water, electrical of thermoelectric for heat exchanger
}

\author{
Akawit Yaidee, Chantana Punlek, Somchai Maneewan \\ Research and Management Center, Faculty of Science, Naresuan University, Thailand
}

\begin{tabular}{l} 
Article Info \\
\hline Article history: \\
Received Aug 7, 2018 \\
Revised Nov 19, 2018 \\
Accepted Feb 25, 2019 \\
\hline
\end{tabular}

Keywords:

Cooling water

Heat exchanger

Thermoelectric module

\begin{abstract}
This paper presents the comparison temperature of thermoelectric (Tec112708) between the series circuit and parallel circuit by adjusting of water flow rate pump and electrical supplying to thermoelectric, the electrical voltage at 8,10 and $12 \mathrm{~V}$, water flow rate in reservoir was $0.015 \mathrm{~kg} / \mathrm{s}$ and $0.025 \mathrm{~kg} / \mathrm{s}$. Experiments perform were 6 hours. The result from the researches, thermoelectric with parallel circuit high temperature more than thermoelectric with series circuit. The parallel circuit of thermoelectric can work better than the series circuit in hot side. The different temperature hot side of parallel circuit with the electrical voltage at 8,10 and $12 \mathrm{~V}$ water flow rate in reservoir was $0.015 \mathrm{~kg} / \mathrm{s}$ temperature average is $22.44{ }^{\circ} \mathrm{C}, 22.90$ ${ }^{\circ} \mathrm{C}, 29.86{ }^{\circ} \mathrm{C}$, and water flow rate in reservoir was $0.025 \mathrm{~kg} / \mathrm{s}$ temperature average is $20.67{ }^{\circ} \mathrm{C}, 26.66^{\circ} \mathrm{C}, 27.69^{\circ} \mathrm{C}$. Thermoelectric with parallel circuit makes the higher temperature more than thermoelectric with series circuit about $33 \%, 37 \%, 44 \%$ water flow rate in reservoir was $0.015 \mathrm{~kg} / \mathrm{s}$ and $30 \%$, $40 \%, 41 \%$ water flow rate in reservoir was $0.025 \mathrm{~kg} / \mathrm{s}$.
\end{abstract}

Copyright (c) 2019 Institute of Advanced Engineering and Science. All rights reserved.

\section{Corresponding Author:}

Chantana Punlek,

Research and Management Center, Faculty of Science,

Naresuan University,

Phitsanulok, 65000, Thailand.

Email: Chantanap@nu.ac.th

\section{INTRODUCTION}

Since Thailand uses a lot of electrical energy, cold energy, and thermal power that are also essential in the household and industrial sectors and necessary for the daily life of the population in the country, so the trend of energy consumption is increased accordingly. The team has been looking for equipment that can produce both cold energy and thermal power which is Thermoelectric. These energies are still used in the household and the team focuses on the households that use these various energy sources but not much, and using of alternative energy is also reduce the environmental impact. The Alternative Energy Development Plan: AEDP 2015 was developed and focused on promoting energy production within the full potential of domestic renewable energy resources. Develop appropriate renewable energy production with considered to the appropriate and benefit in social and environmental dimensions of the community. The Alternative Energy Development Plan: AEDP 2015 [1] consist of The Power Development Plan, The Energy Efficiency Development Plan,The Alternative Energy development Plan, The Oil Development Plan and The Gas Development Plan.The researcher emphasized and tested the heat and cooling energy production for responding and promoting renewable energy and alternative energy. Therefore, the researcher selected a device that can produce the energy to become alternative energy. There is thermoelectric which can produce electrical, heating and cooling; these energies are used in households. The researcher focused on the 
household sector that uses not much energy; moreover, using alternative energy also reduce the environmental impact and reply energy plan too.

Thermoelectric can produce electricity. The thermodynamic phenomenon occurs in materials that can change the different in temperature [2] of the material, heat, and cold and can be reversed. The material that uses hotness to make electricity is Thermoelectric Power (TEP) [3] and material that uses coolness to make electricity is Thermoelectric Cooling (TEC) [4] and can bring electricity that is produced by Thermoelectric [5] to use. Most of the Thermoelectric is applied to systems that produce energy in various forms.

So, this research uses the Thermoelectric that can produce cold energy and thermal power by joining the circuit of Thermoelectric in series and parallel for test efficiency. The experiment is the adjustment to make electricity and the flow rate with Thermoelectric to be appropriate to get a high temperature from Thermoelectric to make energy.

This research is just a comparison temperature of the thermoelectric series circuit and parallel circuit. By adjusting the power supply voltage from the power supply to the thermostat and adjusting the flow rate of the water exchanger heating and cooling. And the results will be applied to other applications.

Thermoelectric Module [6] is made by using the principle of heat pump of semiconductor materials. When the direct electric current is turned on the power to the thermocouple module that use a P-N type semiconductor , and when the current flowing through the semiconductor material is different that will make the electric potential different cause a different in temperature between the two terminals. When the electromotive force flows through a $\mathrm{N}$ type semiconductor that will make the electrons flowing from the negative side of the power supply to the positive side of the power supply and the heat absorbing from another side of the power for release heat out at the end of the semiconductor on the other side.

The hole flowing style of P-type semiconductor is opposite with the flowing style of P-type semiconductor's electrons that means when the electric current flows into the P-type semiconductor cause the flow of hole from the anode to the cathode and the heat absorbing from the anode of P-type semiconductor for release heat out at the cathode then we choose the advantage of both semiconductor to use together in a series of thermoelectric module.

\section{RESEARCH METHOD}

The research of comparing thermoelectric's temperature between the parallel circuit and series have the ventilation of hot and cold by water with the appropriate flowing rate for making high thermoelectric's temperature. The research steps are as follows, making the parallel circuit and series circuit by using the thermoelectric (tec1-12708) (Table. 1) that size is $4 \times 4 \mathrm{~cm}$. Measure the temperature between the hot side and cold side of water block [7], and measure the water's temperature in the tank of hot and cold water by using the thermocouple type $\mathrm{k}$. The heat exchanger uses water to make the drainage of hot side and cold side, water flow rate in reservoir was $0.015 \mathrm{~kg} / \mathrm{s}$ and $0.025 \mathrm{~kg} / \mathrm{s}$ and collect experimental results by data logger every 10 seconds experiments perform were 6 hours. Figure 1. Schematic of the measurement of hot side and cold side water block [8], Figure 2. Motor pump water dc, Figure 3. Schematic of this experimental setup thermoelectric series circuit, Figure 4. Schematic of this experimental setup thermoelectric parallel circuit.

Table 1 Specifications of thermoelectric module TEC1-12708 [9]

\begin{tabular}{lc}
\hline Parameter & Cooling modules \\
Thermoelectric & TEC1-12708 \\
\hline Size $(\mathrm{mm})$ & $40 \mathrm{x} 40$ \\
Module hight $(\mathrm{mm})$ & 3.46 \\
No.of couple (number) & 127 \\
Maximum voltage (volts) & 15.0 \\
Maximum current $(\mathrm{amps})$ & 8.5 \\
Maximum power $($ watts) & 127.5 \\
Maximum hot side temperature $\left({ }^{\circ} \mathrm{C}\right)$ & $160-170$ \\
Maximum different temperature $\left({ }^{\circ} \mathrm{C}\right)$ & 68 \\
Module cost (US\$) & 8 \\
\hline
\end{tabular}

Int J Pow Elec \& Dri Syst, Vol. 10, No. 2, June 2019 : 785 - 791 


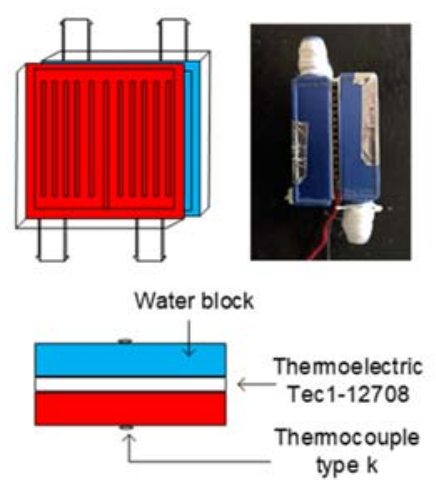

Figure 1. Schematic of the measurement hot side and cold side water block [10]

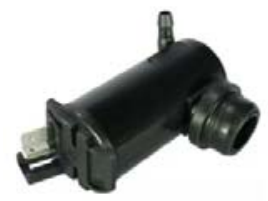

Figure 2. Motor pump water dc

Water flow rate in reservoir was $0.015 \mathrm{~kg} / \mathrm{s}(3 \mathrm{~V})$

Water flow rate in reservoir was $0.025 \mathrm{~kg} / \mathrm{s}(4 \mathrm{~V})$

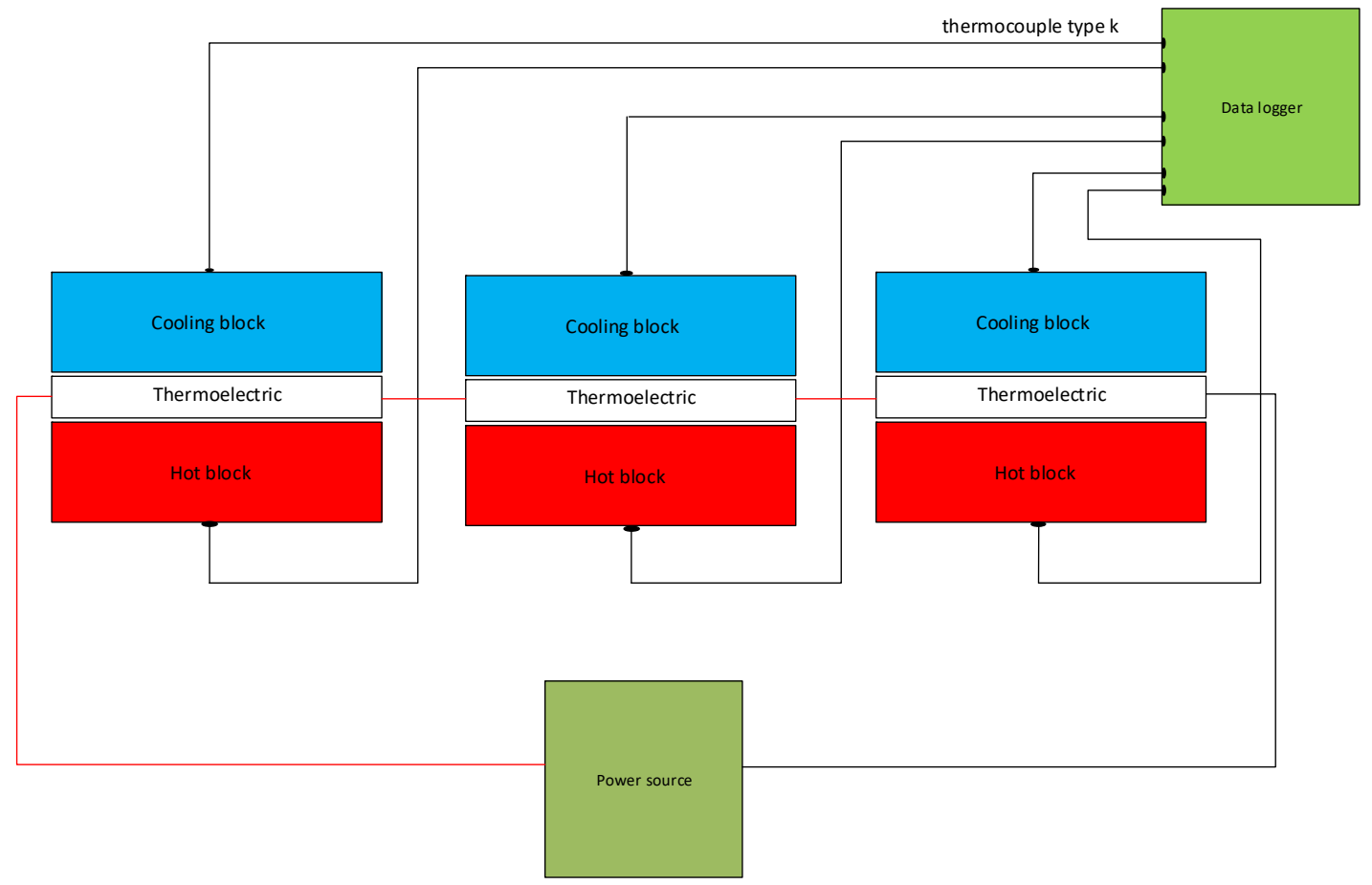

Figure 3. Front view of the thermoelectric series circuit. 


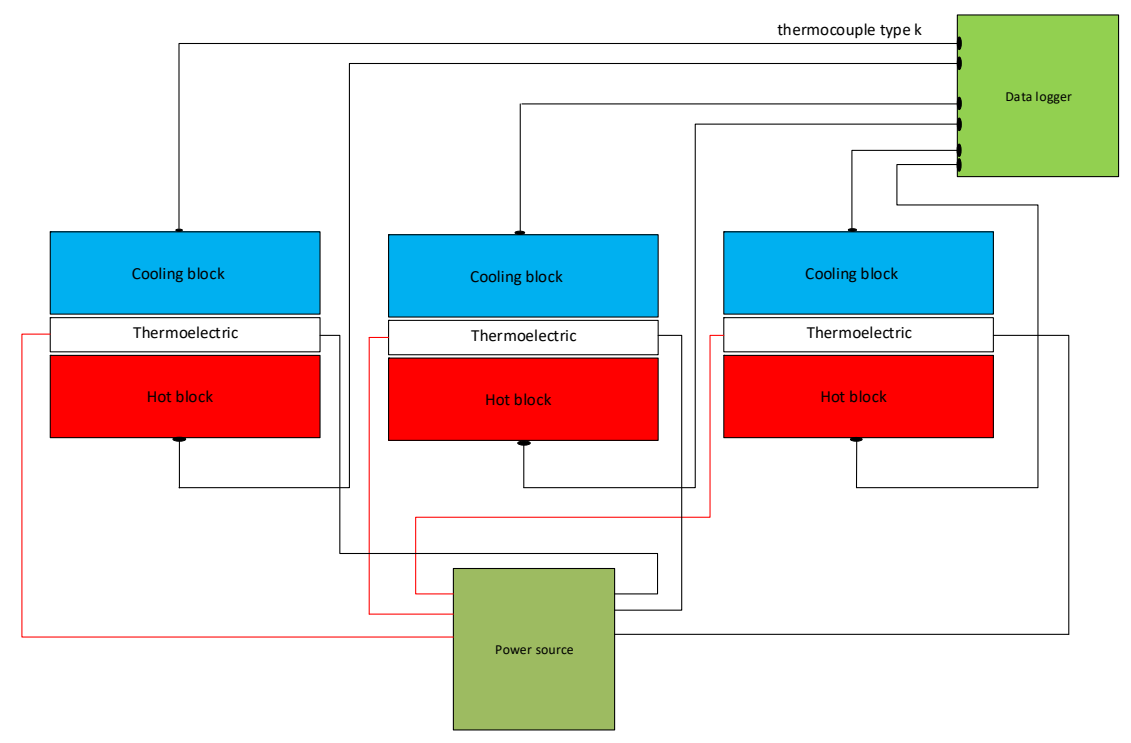

Figure 4. Front view of the thermoelectric parallel circuit.

\section{RESULTS AND ANALYSIS}

This research comparing thermoelectric's temperature between the series circuit and parallel circuit. The electrical voltage at 8,10 and $12 \mathrm{~V}$, and the heat exchanger between the hot side and cold side of thermoelectric by using water. The water flow rate in reservoir was 0.015 and $0.025 \mathrm{~kg} / \mathrm{s}$, and these value is average of temperature from the start research to finished.

\subsection{Compare series circuit and parallel circuit $8 \mathrm{~V}$, water flow rate in reservoir was 0.015 and $0.025 \mathrm{~kg} / \mathrm{s}$}

This research comparing thermoelectric's temperature between series circuit and parallel circuit by using the power supply the electricity to thermoelectric with $8 \mathrm{~V}$ water flow rate in reservoir was $0.015 \mathrm{~kg} / \mathrm{s}$ (3V) as shown in Figure 5, the thermoelectric's circuit of parallel is higher temperature than the series circuit, which the highest temperature of parallel circuit is $65.96 \mathrm{oC}$ and the lowest is $20.87 \mathrm{oC}$, and the highest temperature of series circuit is $41.28 \mathrm{oC}$ and the lowest is $24.68 \mathrm{oC}$, so the different of hot side temperature is $24.68 \mathrm{oC}$.

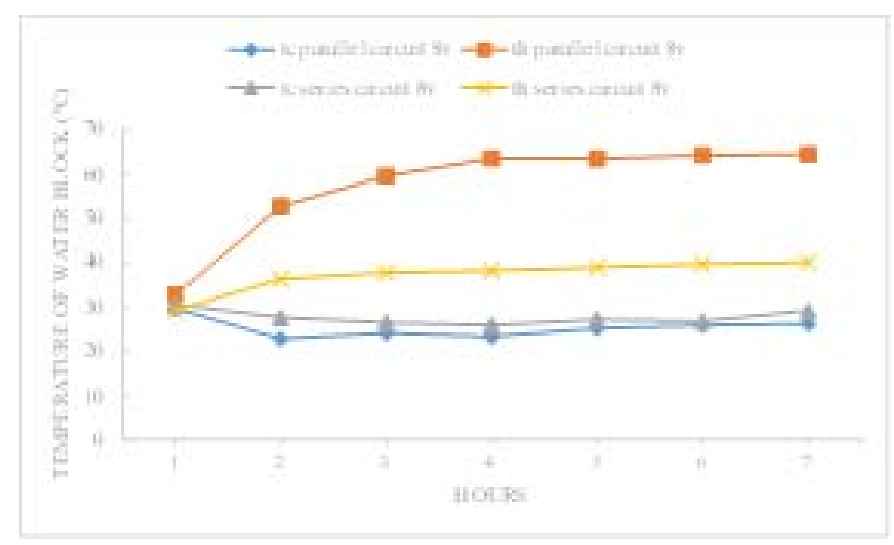

Figure 5. Temperature compare series circuit and parallel circuit the electrical voltage at $8 \mathrm{~V}$, water flow rate in reservoir was $0.015 \mathrm{~kg} / \mathrm{s}$ 
The thermoelectric's circuit of parallel is higher temperature than the series circuit, which the highest temperature of parallel circuit is $65.26^{\circ} \mathrm{C}$ and the lowest is $21.24{ }^{\circ} \mathrm{C}$, and the highest temperature of series circuit is $43.01{ }^{\circ} \mathrm{C}$ and the lowest is $24.91^{\circ} \mathrm{C}$, so the different of hot side temperature is $22.25^{\circ} \mathrm{C}$, water flow rate of $0.025 \mathrm{~kg} / \mathrm{s}$ as shown in Figure 6.

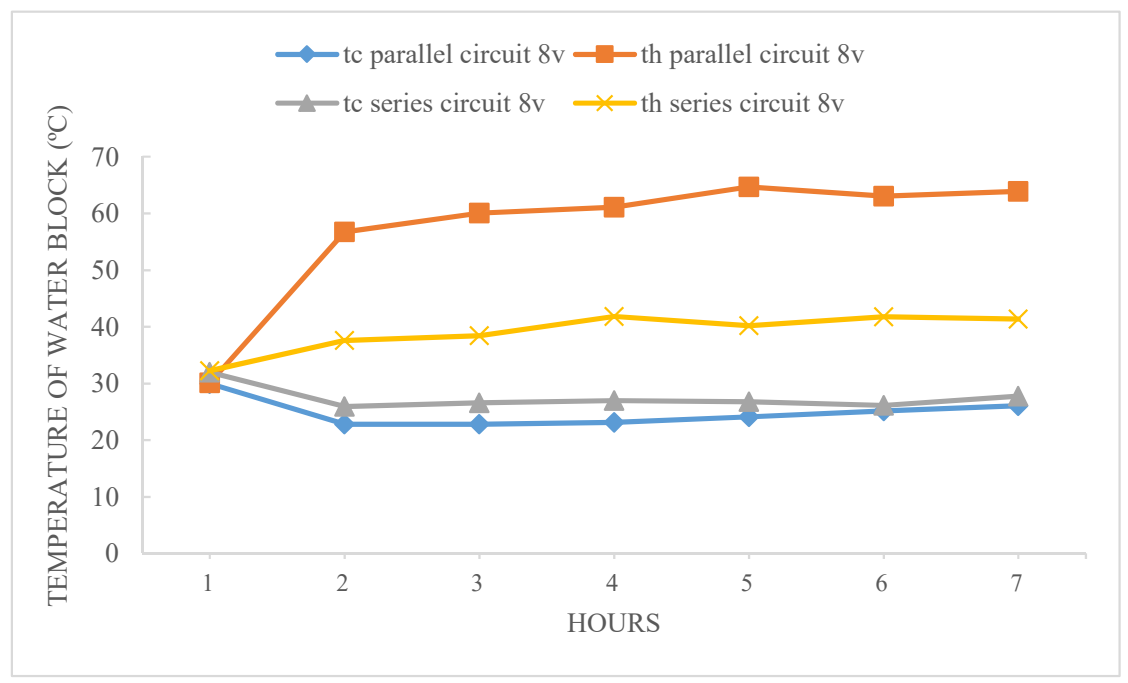

Figure 6. Temperature compare series circuit and parallel circuit the electrical voltage at $8 \mathrm{~V}$, water flow rate in reservoir was $0.025 \mathrm{~kg}$

\subsection{Compare series circuit and parallel circuit $10 \mathrm{v}$, water flow rate in reservoir was 0.015 and $0.025 \mathrm{~kg} / \mathrm{s}$}

This research comparing thermoelectric's temperature between series circuit and parallel circuit by using the power supply the electricity to thermoelectric with $10 \mathrm{~V}$ and water flow rate pumps $3 \mathrm{v}$ is shown in Figure 7, the thermoelectric's circuit of parallel is higher temperature than the series circuit, which the highest temperature of parallel circuit is $75.88 \mathrm{oC}$ and the lowest is $22.36 \mathrm{oC}$, and the highest temperature of series circuit is $43.96 \mathrm{oC}$ and the lowest is $22.43 \mathrm{oC}$, so the different of hot side temperature is $31.92 \mathrm{oC}$.

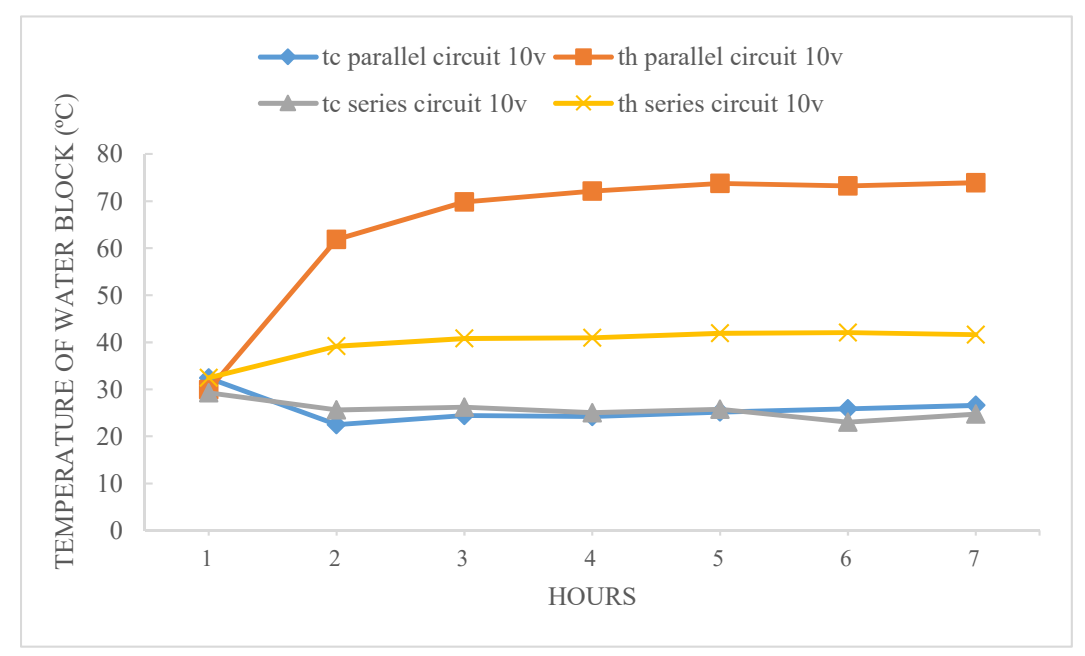

Figure 7. Temperature compare series circuit and parallel circuit the electrical voltage at $10 \mathrm{~V}$, water flow rate in reservoir was $0.015 \mathrm{~kg} / \mathrm{s}$ 
The thermoelectric's circuit of parallel is higher temperature than the series circuit, which the highest temperature of parallel circuit is $73.74{ }^{\circ} \mathrm{C}$ and the lowest is $22.84{ }^{\circ} \mathrm{C}$, and the highest temperature of series circuit is $45.91{ }^{\circ} \mathrm{C}$ and the lowest is $24.15{ }^{\circ} \mathrm{C}$, so the different of hot side temperature is $27.83{ }^{\circ} \mathrm{C}$, the water flow rate $0.025 \mathrm{~kg} / \mathrm{s}$ is shown in Figure 8 .

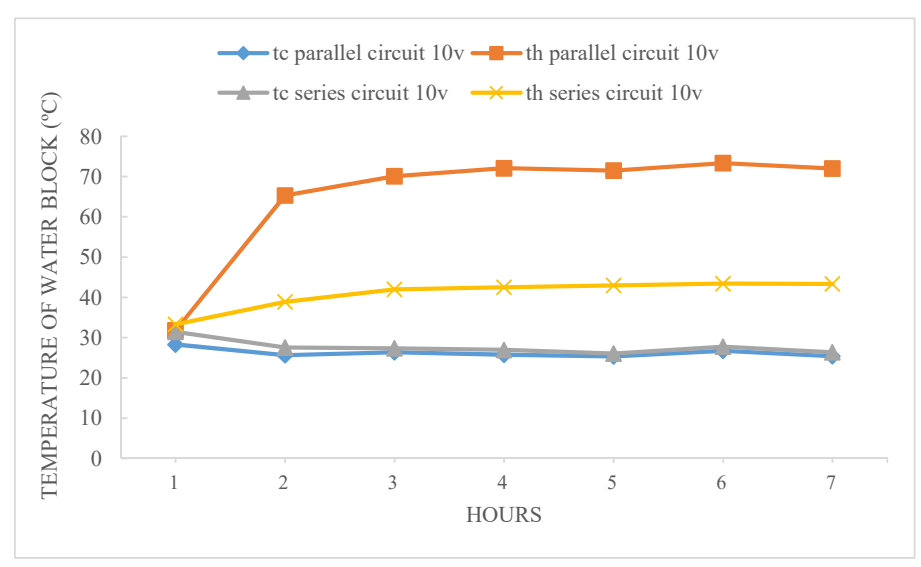

Figure 8. Temperature compare series circuit and parallel circuit the electrical voltage at $10 \mathrm{~V}$, water flow rate in reservoir was $0.025 \mathrm{~kg} / \mathrm{s}$

\subsection{Compare series circuit and parallel circuit the electrical voltage at $12 \mathrm{~V}$, water flow rate in reservoir was 0.015 and $0.025 \mathrm{~kg} / \mathrm{s}$}

This research comparing thermoelectric's temperature between the series circuit and parallel circuit by using the power to supply the electricity to thermoelectric with $12 \mathrm{~V}$ and water flow rate of $0.015 \mathrm{~kg} / \mathrm{s}$ is shown in Figure 9. The thermoelectric's circuit of parallel is the higher temperature than the series circuit, which the highest temperature of the parallel circuit is $88.08 \mathrm{oC}$ and the lowest is $22.75 \mathrm{oC}$, and the highest temperature of the series circuit is $47.17 \mathrm{oC}$ and the lowest is $21.56 \mathrm{oC}$, so the different of hot side temperature is $40.910 \mathrm{C}$.

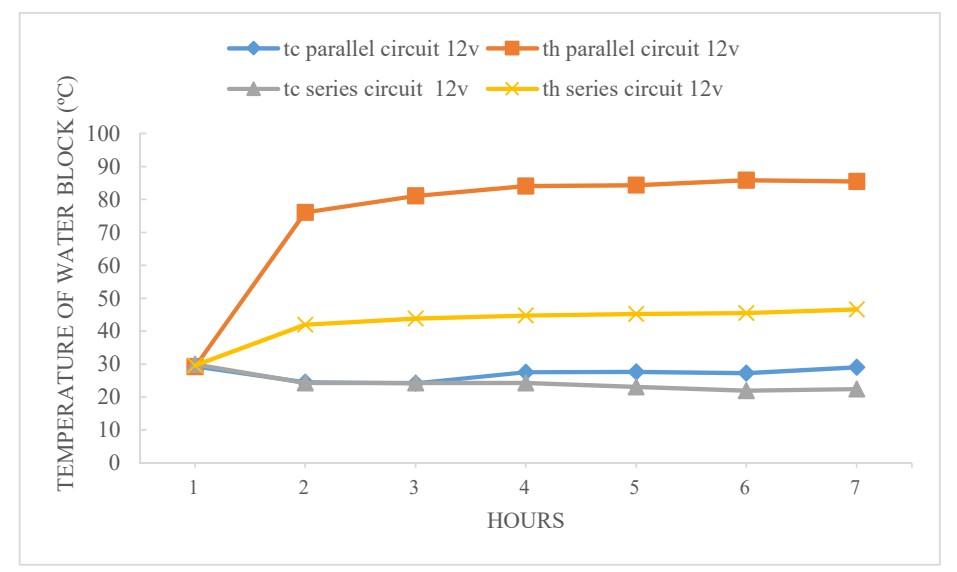

Figure 9. Temperature compare series circuit and parallel circuit the electrical voltage at $12 \mathrm{~V}$, water flow rate in reservoir was $0.015 \mathrm{~kg} / \mathrm{s}$

The thermoelectric's circuit of parallel is higher temperature than the series circuit, which the highest temperature of parallel circuit is $81.84 \mathrm{oC}$ and the lowest is $22.62 \mathrm{oC}$, and the highest temperature of series circuit is $47.87 \mathrm{oC}$ and the lowest is $23.57 \mathrm{oC}$, so the different of hot side temperature is $33.97 \mathrm{oC}$, the water flow rate of $0.025 \mathrm{~kg} / \mathrm{s}$ is shown in Figure 10.

Int J Pow Elec \& Dri Syst, Vol. 10, No. 2, June 2019 : 785 - 791 


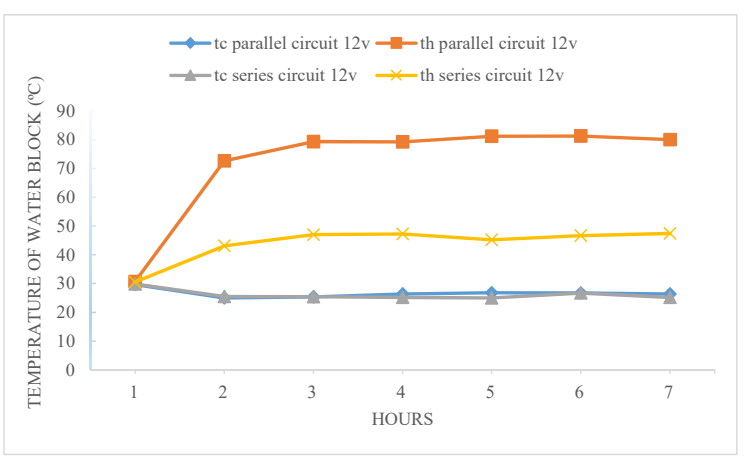

Figure 10. Temperature compare series circuit and parallel circuit the electrical voltage at $12 \mathrm{~V}$, water flow rate in reservoir was $0.025 \mathrm{~kg} / \mathrm{s}$

\section{CONCLUSION}

The research, taking the electrical voltage at 8,10 and $12 \mathrm{~V}$ to the series circuit of thermoelectric, and taking the electric from power supply to pumps, hot side with water flow rate in reservoir was $0.015 \mathrm{~kg} / \mathrm{s}$ have the maximum temperature is $41.28^{\circ} \mathrm{C}, 43.96{ }^{\circ} \mathrm{C}, 47.17{ }^{\circ} \mathrm{C}$, and cold side the minimum temperature is $21.82{ }^{\circ} \mathrm{C}, 22.43{ }^{\circ} \mathrm{C}, 21.56{ }^{\circ} \mathrm{C}$ and water flow rate in reservoir was $0.025 \mathrm{~kg} / \mathrm{s}$ have hot side the maximum temperature is $43.01{ }^{\circ} \mathrm{C}, 45.91{ }^{\circ} \mathrm{C}, 47.87^{\circ} \mathrm{C}$ and cold side the minimum temperature is $24.91{ }^{\circ} \mathrm{C}$, $24.15^{\circ} \mathrm{C}, 23.57^{\circ} \mathrm{C}$.

The research, taking the electrical voltage at $12 \mathrm{~V} 8,10$ and $12 \mathrm{~V}$ to the parallel circuit of thermoelectric, and taking the electric from power supply to pumps, hot side with water flow rate in reservoir was $0.015 \mathrm{~kg} / \mathrm{s}$ have the maximum temperature is $65.96^{\circ} \mathrm{C}, 75.88^{\circ} \mathrm{C}, 88.08^{\circ} \mathrm{C}$, and cold side the minimum temperature is $20.87^{\circ} \mathrm{C}, 22.36^{\circ} \mathrm{C}, 22.75^{\circ} \mathrm{C}$ and water flow rate in reservoir was $0.025 \mathrm{~kg} / \mathrm{s}$ have hot side the maximum temperature is $65.26{ }^{\circ} \mathrm{C}, 73.74{ }^{\circ} \mathrm{C}, 81.84{ }^{\circ} \mathrm{C}$ and cold side the minimum temperature is $21.24{ }^{\circ} \mathrm{C}$, $22.84^{\circ} \mathrm{C}, 22.62{ }^{\circ} \mathrm{C}$.

So, the parallel circuit of thermoelectric can work better than the series circuit in hot side. The different temperature hot side of parallel circuit with the electrical voltage at $12 \mathrm{~V} 8 \mathrm{v}, 10 \mathrm{v}$ and $12 \mathrm{~V}$, water flow rate in reservoir was $0.015 \mathrm{~kg} / \mathrm{s}$ temperature average is $22.44{ }^{\circ} \mathrm{C}, 22.90{ }^{\circ} \mathrm{C}, 29.86{ }^{\circ} \mathrm{C}$, and water flow rate in reservoir was $0.025 \mathrm{~kg} / \mathrm{s}$ temperature average is $20.67^{\circ} \mathrm{C}, 26.66^{\circ} \mathrm{C}, 27.69^{\circ} \mathrm{C}$.

\section{ACKNOWLEDGEMENTS}

The authors are grateful Energy Policy and Planning Office, Ministry of Energy, Thailand (EPPO) for providing financial support and Research and Management Center, Faculty of Science Naresuan University, Phitsanulok, Thailand. This support the research to succeed.

\section{REFERENCES}

[1] "Alternative Energy Development Plan: AEDP2015 Energy Policy and Planning Office," Ministry of Energy, Thailand (EPPO) http://www.eppo.go.thFggg. Accessed 20 April 2017.

[2] Liang X., et al., "Comparison and parameter optimization of a two-stage thermoelectric generator using high temperature exhaust of internal combustion engine," Applied Energy, vol. 130(1), pp. 190-199, 2014.

[3] Maneewan, S, Dr. Anusorn Vorasingha, (2553). "Comparison Power Generation by Using Thermoelectric Module Between Cooling Module and Power Module," Naresuan University.

[4] Chesta Ruttanapun, "Thermoelectric Properties Improvement of Cu-based Delafossiteby Partial Substitution Doping," Journal of science ladkrabang, vol. 23(2), 2014.

[5] Synchrotron Thailand central lab. Thermoelectrics. www.slri.or.th/th Accessed 28 April 2017.

[6] Maneewan, S “Thermoelectric clean technology,” Technic Magazines, vol. 21(235), pp. 145-151, 2004.

[7] Muhammad Fairuz Remelia,b, Abhijit Date, Bradley Orr, Lai Chet Ding, Baljit Singh,Nor Dalila Nor Affandi, Aliakbar Akbarzadeh, "Energy Conversion and Management 111," pp. 147-157, 2016.

[8] M. Hasan Niaa, A. Abbas Nejad, A.M. Goudarzi, M. Valizadeh, P. Samadian, "Energy Conversion and Management," vol. 84, pp. 305-310, 2014.

[9] "Specification of TE Modules," Available from: https://hong-lang.en.alibaba.com. Accessed 4 April 2017.

[10] Murat Gökçek, "Fatih Şahin Experimental performance investigation of minichannel watercooled-thermoelectric refrigerator Case Studies," in Thermal Engineering, vol. 10, 54-62, 2017.

Experiment study investigation compare temperature series circuit and the parallel ... (Akawit Yaidee) 